Case Report

\title{
"Recurrent Papillary Necrosis and Nephrocalcinosis Induced by Nonsteroidal Anti-Inflammatory Drugs for Gouty Arthritis Associated with Congenital Chloride-Losing Diarrhea: A Major Risk for Kidney Loss"
}

\author{
Kamel El-Reshaid (D), ${ }^{1}$ Shaikha Al-Bader, ${ }^{2}$ and Hossameldin Sallam ${ }^{2}$ \\ ${ }^{1}$ Department of Medicine, Faculty of Medicine, Kuwait University, Kuwait City, Kuwait \\ ${ }^{2}$ Department of Medicine, Nephrology Unit, Al-Amiri Hospital, Ministry of Health, Kuwait City, Kuwait \\ Correspondence should be addressed to Kamel El-Reshaid; kamel_elreshaid@yahoo.com
}

Received 9 June 2021; Accepted 5 October 2021; Published 16 October 2021

Academic Editor: Yoshihide Fujigaki

Copyright (c) 2021 Kamel El-Reshaid et al. This is an open access article distributed under the Creative Commons Attribution License, which permits unrestricted use, distribution, and reproduction in any medium, provided the original work is properly cited.

\begin{abstract}
Congenital chloride-losing diarrhea (CCLD) is a rare genetic disorder due to autosomal recessive mutation in the SLC26A3 gene on chromosome 7. It is characterized with chronic watery diarrhea with high fecal chloride ( $\mathrm{Cl}:>90 \mathrm{mmol} / \mathrm{L})$, low potassium (K), and metabolic alkalosis with low urinary $\mathrm{Cl}$ and $\mathrm{K}$. The overall long-term prognosis is favorable with optimal life-long salt and $\mathrm{K}$ supplementation. In this case report, we describe a man with progressive renal failure and small kidneys that showed nephrocalcinosis and papillary necrosis. His disease was diagnosed since birth and was confirmed by our tests. He was incompliant with therapy and had developed gout. The latter complication of his disease has led to excessive NSAID use over the past years. Reinstitution of diet, drug therapy, and allopurinol had stabilized his renal disease for 1 year of follow-up. In conclusion, excessive analgesic use is a risk factor for renal failure in CCLD.
\end{abstract}

\section{Introduction}

Congenital chloride-losing diarrhea (CCLD) is a rare genetic disorder due to autosomal recessive mutation in the SLC26A3 gene on chromosome 7. The latter leads to defective intestinal chloride-bicarbonate exchanges, in epithelial sodium $(\mathrm{Na}) /$ hydrogen $(\mathrm{H})$ transport through the $\mathrm{Na}$ / $\mathrm{H}$ exchangers (NHE2 and/or NHE3), with the resultant intestinal loss of chloride and retention of bicarbonate [1]. Consequently, the renin-angiotensin-aldosterone system is activated with $\mathrm{Na}$ reabsorption, potassium (K) excretion, and hypokalemia [2]. The first description of the disease was in 1945 by Gamble and Darrow, and nearly 250 cases have been reported to date [3]. Most of the cases have been reported from Finland, and their calculated prevalence was 1 in 43,000 newborns [4]. In Arab, only few cases have been reported in Saudi Arabia and Kuwait [5, 6]. The overall longterm prognosis is favorable with optimal life-long salt and $\mathrm{K}$ substitution though complications such as renal disease, hyperuricemia, inguinal hernias, spermatoceles, and decreased fertility reported in incompliant patients [7]. In this case report; we describe an adult patient, with this rare disease, who lost his kidneys due to chronic analgesic abuse for maltreated gouty arthritis.

\section{The Case}

A 30-year-old man presented with progressive nausea and vomiting over a few weeks. His past medical history revealed watery diarrhea since the age of 6 months. His investigations at that time have shown high stool chloride $(\mathrm{Cl})>90 \mathrm{mmol} / \mathrm{L}$ with low serum and urinary $\mathrm{Cl}$, potassium $(\mathrm{K})$ and high uric acid (UA). Moreover, he had metabolic alkalosis. He had received high-salt diet in addition to slow $\mathrm{K}$ and calcium tablet. Twelve years ago, he had developed recurrent attacks of joint pains with high uric acid which was treated with 

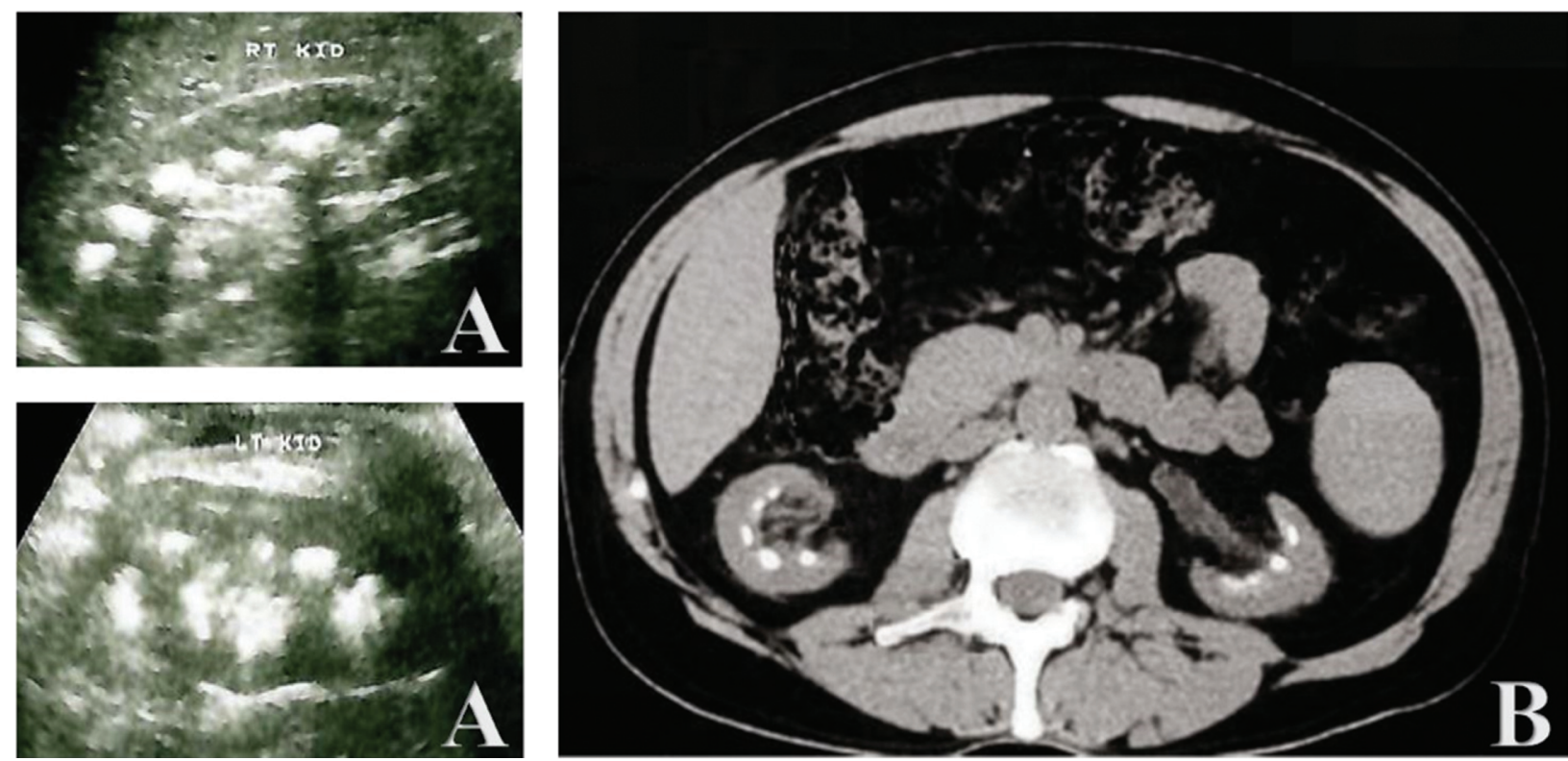

FIGURE 1: Ultrasound showing a small right kidney with nephrocalcinosis and calcified papilla (a) that was confirmed by CT scan (b).

multiple NSAIDs. On his initial presentation, the patient was conscious, oriented X3, and without distress of shortness of breath or pain. Blood pressure was $180 / 110 \mathrm{mmHg}$. He was afebrile with a body weight of $104 \mathrm{~kg}$. He did not have jugular venous distension and oedema. Systemic examination did not show abnormality including lung auscultation. Laboratory investigations showed normal peripheral leucocytic and platelets counts. Hemoglobin was $104 \mathrm{~g} / \mathrm{L}$ with normal MCV, transferrin saturation\%, and vitamin B12. Serum urea and creatinine were elevated at $40 \mathrm{umol} / \mathrm{L}$ and $650 \mathrm{umol} / \mathrm{L}$, respectively. Serum electrolytes revealed low sodium, $\mathrm{Cl}$, calcium, and $\mathrm{K}$ at $129,93,1.8$, and $2.9 \mathrm{mmol} / \mathrm{L}$, respectively. Serum UA was elevated at $700 \mathrm{umol} / \mathrm{L}$. Liver tests were normal with serum albumin at $41 \mathrm{~g} / \mathrm{L}$. Serum cholesterol and TSH were normal. Serum $\mathrm{pH}$ was 7.5 , and bicarbonate was at $32 \mathrm{mmol} / \mathrm{L}$. Urine routine and microscopy showed $1(+)$ proteinuria without hematuria and pyuria. Serum complements ( $\mathrm{C} 3$ and $\mathrm{C} 4)$, IgA level, and protein electrophoresis were normal. Anti-CCP, ANA, anti-ds DNA, ANCA, antiGBM-antibodies, hepatitis B surface antigen, and anti-HCV antibodies were negative. Stool tests were negative for ova, parasites, and occult blood. Stool $\mathrm{Cl}$ was $120 \mathrm{mmol} / \mathrm{L}$ with zero urine $\mathrm{Cl}$ and $\mathrm{K}$. Chest X-ray and ECG were normal. Abdominal and pelvic ultrasound did not show abnormality except for bilateral small kidneys at $8 \mathrm{~cm}$ with thin and echogenic cortex and few foci of papillary calcifications which were confirmed by CT scan examination (Figure 1). He was treated initially with intravenous $\mathrm{KCl}$ till $\mathrm{K}$ was $>4$ then with normal saline till establishing the euvolumic state. Subsequently, he required high salt and water with oral $\mathrm{K}$ supplementation (600 mg X2). Omeperazole $20 \mathrm{mg}$ was added to protect $\mathrm{KCl}$ gastritis. His high uric acid was controlled with allopurinol $300 \mathrm{mg}$ daily. With such measures, his electrolytes were corrected and serum creatinine decreased to $420 \mathrm{umol} /$ L. On follow-up, he remained asymptomatic and his serum creatinine remained $<500 \mathrm{umol} / \mathrm{L}$ for 1 year.

\section{Discussion}

Patients with CCLD have chronic watery diarrhea with high fecal Cl (>90 mmol/L), low K, and metabolic alkalosis with low urinary $\mathrm{Cl}$ and $\mathrm{K}$ [4]. Diagnosis is usually suspected with fetal abdominal distension and ultrasound features of polyhydramnios, hyperechoic bowel loops, honey comb appearance of the bowel, and dilated bowel loops with normal peristalsis [8]. Its differential diagnosis include Hirschsprung's disease, meconium ileus, anal atresia, and volvulus [9]. However, the characteristic laboratory findings assist in diagnosis and avoidance of unnecessary surgical interventions. Interestingly, it is the only diarrhea that produces metabolic alkalosis rather than metabolic acidosis. It can be differentiated from Barter's disease by having severe watery diarrhea, dehydration, failure to thrive, abdominal distention, and its electrolyte abnormalities. Contrary to Barter's, urine $\mathrm{K}$ is low with high $\mathrm{Cl}$ and its ease of correction of hypo K. Early diagnosis and treatment, with adequate salt and $\mathrm{K}$, are essential for normal growth and development and prevention of other severe complications. The optimal dosage of electrolytes are $\mathrm{Na}$ $6 \mathrm{mmol} / \mathrm{kg} /$ day, $\mathrm{K} 6.5 \mathrm{mmol} / \mathrm{kg} /$ day, and $\mathrm{Cl}$ ranging from $12.5 \mathrm{mmol} / \mathrm{kg} / \mathrm{day}, \mathrm{mmol} / \mathrm{kg} /$ day in infants, and less in older patients $[5,7]$. The long-term disease complications have been attributed to chronic hypovolemia-induced nephrocalcinosis [10]. Virtually the majority of filtered $\mathrm{Ca}$ is absorbed passively in the paracellular route in the proximal convoluted tubules and ascending limb of Henle parallel to sodium. Only $10 \%$ is absorbed inversely to $\mathrm{Na}$ in the distal nephron [11]. Hence, with severe volume depletion, reabsorption of $\mathrm{Ca}$ is impaired leading to urine supersaturation and crystal precipitation with papillary calcification and nephrocalcinosis as in our patients. Moreover, maltreated gout, with NSAIDs, was a contributing factor in his papillary renal disease [12]. In conclusion; patients with CCLD should be adequately treated with salt and $\mathrm{K}$ supplementation and avoid NSAIDS for their associated gout. 


\section{Conflicts of Interest}

The authors declare no conflicts of interest regarding the publication of this paper.

\section{References}

[1] M. R. Dorwart, N. Shcheynikov, D. Yang, and S. Muallem, "The solute carrier 26 family of proteins in epithelial ion transport," Physiology, vol. 23, no. 2, pp. 104-114, 2008.

[2] M. W. Musch, D. L. Arvans, G. D. Wu, and E. B. Chang, "Functional coupling of the downregulated in adenoma $\mathrm{Cl}^{-}$/ base exchanger DRA and the apical $\mathrm{Na}^{+} / \mathrm{H}^{+}$exchangers NHE2 and NHE3," American Journal of Physiology-Gastrointestinal and Liver Physiology, vol. 296, no. 2, pp. G202-G210, 2009.

[3] N. M. Kamal, H. Y. Khan, M. H. F. El-Shabrawi, and L. M. Sherief, "Congenital chloride losing diarrhea," Medicine, vol. 98, no. 22, Article ID e15928, 2019.

[4] C. Holmberg, "Congenital chloride diarrhoea," Clinics in Gastroenterology, vol. 15, no. 3, pp. 583-602, 1986.

[5] A. M. A. Abdullah, S. M. Katugampola, M. A. Abdullah, K. A. R. Adam, and N. Al-Jishi, "Congenital chloride-losing diarrhea in Saudi children," Annals of Saudi Medicine, vol. 10, no. 4, pp. 389-393, 1990.

[6] M. M. Lubani, K. I. Doudin, D. C. Sharda et al., "Congenital chloride diarrhoea in Kuwaiti children," European Journal of Pediatrics, vol. 148, no. 4, pp. 333-336, 1989.

[7] S. Hihnala, P. Höglund, L. Lammi, J. Kokkonen, T. Örmälä, and C. Holmberg, "Long-term clinical outcome in patients with congenital chloride diarrhea," Journal of Pediatric Gastroenterology \& Nutrition, vol. 42, no. 4, pp. 369-375, 2006.

[8] N. Rose, P. Kaplan, S. Scott, A. Kousoulis, and R. Librizzi, "Prenatal presentation of congenital chloride diarrhea: clinical report and review of the literature," American Journal of Perinatology, vol. 9, no. 5-6, pp. 398-400, 1992.

[9] E. R. Peters and O. F. Redwin, "Ultrasound in the intrauterine diagnosis and treatment of fetal abnormalities," Clinical Obstetrics and Gynecology, vol. 25, no. 4, pp. 753-771, 1982.

[10] S. Wedenoja, T. Örmälä, U. B. Berg et al., "The impact of sodium chloride and volume depletion in the chronic kidney disease of congenital chloride diarrhea," Kidney International, vol. 74, no. 8, pp. 1085-1093, 2008.

[11] P. A. Friedman, "Codependence of renal calcium and sodium transport," Annual Review of Physiology, vol. 60, no. 1, pp. 179-197, 1998.

[12] R. S. Nanra, J. Stuart-Taylor, A. H. de Leon, and K. H. White, "Analgesic nephropathy: etiology, clinical syndrome, and clinicopathologic correlations in Australia," Kidney International, vol. 13, no. 1, pp. 79-92, 1978. 